\title{
A MÁSCARA COMO BASE PARA O TREINAMENTO DO ALUNO-ATOR
}

\author{
LA MÁSCARA COMO BASE PARA EL ENTRENAMIENTO \\ ALUMNO-ACTOR
}

\section{THE MASK AS THE BASIS FOR STUDENT-ACTOR TRAINING}

\author{
Maria de Fátima de Souza Moretti (Sassá Moretti) ${ }^{1}$
}

\begin{abstract}
RESUMO
Neste artigo identificamos as contribuições da máscara para o treinamento do aluno-ator, tendo como base os princípios da máscara neutra. Destacamos o trabalho desenvolvido com alunos de duas universidades. Para chegar ao trabalho da máscara, passamos pela disciplina Improvisação I, na qual temos acesso à pedagogia de Viola Spolin e de Jacques Lecoq. Em seguida chegamos ao Teatro de Animação I, no qual apresentamos aos alunos-atores o universo da máscara, iniciando pela neutra, conforme Jacques Copeau e Jacques Lecoq. A máscara neutra não tem uma expressão definida, passa a sensação física da calma e equilíbrio na tentativa de proporcionar ao aluno-ator o estado de neutralidade. Depois, trabalham-se as máscaras larvárias, bem maiores que o rosto humano. Elas levam um acento forte, ou do nariz ou das bochechas, e têm aparências diversas.
\end{abstract}

PALAVRAS-CHAVE: Ator. Máscara neutra. Máscara larvária. Jogo.

\section{RESUMEN}

En este artículo identificamos las contribuciones de la máscara para el entrenamiento del alumno-actor, teniendo como base los principios de la máscara neutra. Destacamos el trabajo desarrollado con alumnos de dos universidades. Para llegar a las máscaras, pasamos por la disciplina Improvisación I, en la cual tenemos empezamos con la pedagogía de Viola Spolin y de Jacques Lecoq. En seguida llegamos al Teatro de Animación I, en el que presentamos a los alumnos-actores el universo de la máscara, iniciando por la neutral, según Jacques Copeau y Jacques Lecoq. La máscara neutra no tiene una expresión definida, pasa la sensación física de la calma y equilibrio en el intento de proporcionar al alumno-actor el estado de neutralidad. Después, se trabajan las máscaras larvares, mucho más grandes que el rostro humano. Elas possuem nariz ou bochechas muito expressivas, bem como aparências diversas.

PALABRAS CLAVE: Actor. Máscara neutral. Máscara larvares. Juego.

\footnotetext{
1 Professora doutora da Universidade Federal de Santa Catarina (UFSC). Início de projeto de pós-doutorado na Universidade de Strasbourg, França, com o professor PhilipeChoulet, em março de 2019 a fevereiro de 2020. Tema central da pesquisa: "O objeto na cena contemporânea".
} 


\begin{abstract}
In this article we identify the contributions of the mask to student-actor training, based on the principles of the neutral mask. We highlight the work developed with students from two universities. In order to get to the mask work, we go through the discipline Improvisation I, in which we get in toch with the pedagogy of Viola Spolin and Jacques Lecoq. Right after, we arrived at the Theater of Animation I, in which we introduce the student actors to the universe of the mask, starting with the neutral one, according to Jacques Copeau and Jacques Lecoq. The neutral mask has no defined expression, it transmits the physical sensation of calm and balance in an attempt to provide the student-actor with the state of neutrality. Then, the larval masks are worked, much larger than the human face. They have nose or cheeks very expressives, as well as different appearances.
\end{abstract}

KEYWORDS: Actor. Neutral mask. Larva mask. Play.

$$
* * *
$$

\title{
A máscara neutra: algumas considerações
}

Jacques Copeau, em sua escola Vieux Colombier, já utilizava, em 1921, máscaras ditas nobres para o treinamento do ator, para exaltar a expressividade do corpo do ator ao esconder um rosto por demais expressivo. No início, diz Suzanne Bing (2000), principal colaboradora de Copeau, eram utilizados véus ou uma espécie de touca que envolvia as cabeças dos atores para esconder os rostos. Em um momento seguinte, cada ator passou a fabricar sua própria máscara em papel machê para trabalhar a neutralidade. Copeau pretendia, em nome da boa qualidade no desempenho dos atores, criar uma nova geração de artistas, que seriam os responsáveis por essa mudança de comportamento.

Valendo-se dessas proposições, há muito estudadas por Coupeau, Jaques Lecoq funda sua escola e nela utiliza uma pedagogia pautada no uso da máscara neutra como um caminho para a preparação do ator. É importante ressaltar que Lecoq trata a questão do "neutro" como uma busca pela limpeza de movimentos e pela disponibilidade do ator para o jogo.

Para trabalhar com seus atores, Jacques Lecoq contratou Amleto Sartori, grande artesão italiano, especialista em máscaras, para que este construísse uma máscara "neutra", em couro, uma máscara que deixasse o ator livre para todas as possibilidades de atuação, dando a seu corpo a neutralidade de uma página branca. Assim, contrariamente ao ator 
tradicional, o ator ocidental passa a empregar uma máscara de trabalho sem passado, sem expressões premeditadas. O que se quer da máscara neutra é o novo. $\mathrm{O}$ ator deverá reinventar sempre, logicamente guardando os princípios de utilização dela, que o fará:

[...] olhar com toda a cabeça e não apenas com os olhos; estar sempre em estado de alerta, e trabalhar sempre com o máximo de energia; é preciso atravessar a máscara e lhe carregar de conteúdos humanos, isto é, entrar num jogo maior que aquele do jogo cotidiano. [...] A máscara neutra é um objeto particular. É um rosto, dito neutro, em equilíbrio, que propõe a sensação física da calma. Esse objeto colocado no rosto deve servir para que se sinta o estado de neutralidade que precede a ação, um estado de receptividade ao que nos cerca, sem conflito interior. Trata-se de uma máscara de referência, uma máscara de fundo, uma máscara de apoio para todas as outras máscaras. [...] Quando o aluno sentir esse estado neutro do início, seu corpo estará disponível, como uma página em branco, na qual poderá inscrever-se a "escrita" do drama. (LECOQ, 2010, p. 69).

Para intensificar os aspectos técnicos e aqueles referentes ao jogo,

Lecoq estrutura todo o trabalho com a máscara, deixando claro que uma boa máscara de teatro pode mudar de expressão dependendo das expressões do corpo do ator. É necessária uma busca intensa de diferentes corpos com movimentos, ações e estados para proporcionar mudanças nas expressões da máscara.

Esta é a máscara de base que conduz ao uso das outras máscaras. É com esta máscara que o ator se prepara para usar todas as outras. É uma máscara sem expressão particular, nem personagem típico, que não ri, nem chora, que não é triste, nem alegre e que se apoia no silêncio, no estado de calma. (LECOQ, 1987, p. 21).

Para muitos diretores, o uso da máscara neutra é a melhor forma de trabalhar a formação do ator. Peter Brook, em entrevista, fala sobre o treinamento de alunos adotado por muitos encenadores:

Colocamos no aluno uma máscara neutra branca, vazia. No momento em que o rosto é coberto por esta máscara, o aluno vive uma sensação de estupefato: de repente temos a consciência que o nosso rosto, com o qual vivemos e que sabemos que transmite todo o tempo alguma coisa, desapareceu. Provocamos uma sensação extraordinária de liberação. A primeira vez que fazemos este exercício é sem dúvida um grande momento: nos encontramos momentaneamente liberados de nossa própria subjetividade. Isto revela imediatamente a consciência do corpo. (BROOK, 1988, p. 89).

O que Peter Brook nos diz foi perfeitamente identificado no decorrer dos exercícios com os nossos alunos. As reações foram as mais diversas possíveis: desde alguns que tomavam consciência do corpo e se liberavam, até outros, que inicialmente se fechavam sem conseguir resultados. A 
máscara neutra é signo de várias emoções, seu uso não passa despercebido. Ela é muito amada ou muito criticada.

O italiano Dario Fo, ao se referir às máscaras de personagens, diz que no princípio o ator se sente desajeitado ao usá-las, mas com o tempo supera e consegue a espontaneidade. Fo diz ainda que, "enquanto atua com a máscara, os gestos do ator devem ser grandiosos e exagerados" (FO, 1991, p. 8). A partir dessas informações, podemos perceber que a máscara é realmente um dos principais instrumentos para o trabalho do ator na contemporaneidade. Assim, vamos perceber que Dario Fo e Lecoq buscam igualmente os gestos limpos e precisos, grandiosos na visão de Dario Fo, ou mínimos na visão de Lecoq.

\section{Para desbloquear}

$\mathrm{Na}$ busca da preparação do aluno-ator, trilhamos há muito tempo um caminho que vai do objeto imaginário à máscara. $\mathrm{Na}$ disciplina Improvisação I, com Viola Spolin, buscamos o imaginário nas improvisações silenciosas, passando pelo gramelô até chegar à palavra, trabalhando o gestual, as ações e outros recursos. A improvisação, neste caso, é um preparatório para o uso da máscara. Também Lecoq se utiliza das improvisações silenciosas para preparar seu ator para receber a máscara neutra. Descrevemos a seguir as impressões com a máscara neutra a partir de exercícios praticados em sala de aula, em que se estabelece um paralelo com os fundamentos dos pedagogos e diretores acima citados.

\section{Construção das máscaras neutras e exercícios com elas}

No Curso de Bacharelado em Artes Cênicas, na Universidade Federal de Santa Catarina (UFSC), trabalhamos com teatro de animação, que contempla as disciplinas teatro de bonecos, de máscaras, de objetos e de sombras.

A disciplina de máscaras inclui a construção delas pelos alunos, fato

que se transforma num dos momentos mais ricos do semestre. Esse fazer a própria máscara é também uma maneira de perpetuar esse saber, e, a nosso 
ver, isso é muito relevante. No primeiro dia de aula costumamos reunir todos os alunos e dar-lhes instruções, apresentando os materiais e as etapas do trabalho a ser desenvolvido. Em seguida colocamos uma música tranquila e damos início à confecção da primeira máscara diretamente no rosto de um dos alunos. Cria-se um momento tenso, pois o aluno permanece deitado com um canudo no nariz, uma touca na cabeça e, muitas vezes, por opção, plástico nos olhos, além de creme na pele do rosto para receber o gesso, que, com a consistência correta, permanece de 1 a 2 minutos antes de ser removido. Quando o gesso seca, pedimos que o aluno se levante e que faça algumas caretas para que o gesso se solte delicadamente do rosto. Assim obtemos o molde negativo. $\mathrm{O}$ olhar do discente nesse primeiro momento em que ele contempla a imagem de seu rosto no gesso é muito significativo. Em seguida, depois do molde pronto, passamos a corrigir as imperfeições da máscara com o uso de argila, tampando os orifícios da narina, e adicionando argila nas laterais quando necessário. A seguir passamos vaselina e preenchemos o molde com gesso-pedra. Temos então o molde positivo. Depois de algumas horas, cada aluno retira a parte de fora do artefato, o gesso comum, com a ajuda de um pequeno martelo, e fica-se então com o molde em gesso-pedra. Depois desse processo, chegamos ao momento de confecção das máscaras neutras. Com argila eliminamos os traços de expressão dos rostos, o que é seguido da papietagem dos moldes, com a utilização de cola de trigo. Após esse processo, fazemos os recortes nos olhos, nas narinas e nas laterais da máscara, finalizando-a. Nossa versão de máscara apresenta algumas diferenças daquela proposta por Lecoq, pois nossas máscaras possuem aberturas menores para os olhos, o que diminui consideravelmente o campo visual do ator. Isso faz com que os alunos-atores se concentrem mais em seus próprios corpos e os coloquem em estado de prontidão para poder perceber o outro com quem dividem o espaço. Essa decisão foi baseada na ideia de que a pequena abertura ajuda o aluno-ator em sua concentração e em seu olhar interior. É necessário manter a calma também, pois a respiração com a máscara é um pouco mais difícil. Como 
semelhança, a construção dessas máscaras é pensada para que exista alguma distância entre o rosto do ator e ela. Segundo Lecoq,

Uma máscara neutra, como todas as outras máscaras, aliás, não pode aderir ao rosto. Tem de conservar uma certa distância do rosto, pois é justamente com essa distância que o ator pode verdadeiramente jogar. Também é preciso que ela seja ligeiramente maior do que o rosto. A dimensão real de um rosto, que se encontra, por exemplo, nas máscaras mortuárias, não facilita o jogo nem sua força expressiva. Essa observação é válida para todas as máscaras. (LECOQ, 2010, p. $69)$.

Percebe-se que Lecoq salienta a importância do afastamento da máscara do rosto do ator, o que consideramos um respiro necessário para uma boa atuação. Consegue-se esse efeito no momento em que se trabalha a argila para eliminar as expressões do rosto. Dessa forma, os moldes acabam tendo um tamanho maior que o dos rostos. Além disso, para aqueles que não conseguiram o afastamento necessário para uma boa atuação, são usados pequenos pedaços de espuma nas faces, no queixo ou na testa. Suzanne Bing reforça o pensamento desses momentos vividos com os alunos quando afirma que:

En el acto mismo de modelar un rostro que se observa, se prepara el conocimiento del rostro humano, y el uso posterior de la máscara hasta niveles superiores. El procedimiento material, la labranza del barro, la práctica del modelado, las investigaciones, con el cartón, son los más exaltantes y educativos entre los trabajos manuales. (BING, 2000, p. 78). ${ }^{2}$

É muito preciosa essa visão de Suzanne Bing sobre a confecção das máscaras. Realmente, trabalhar com as mãos nos proporciona sempre muita descontração, relaxamento e bem-estar, principalmente em se tratando da confecção da cópia de nosso próprio rosto.

A etapa seguinte de nossas aulas consiste na neutralização das máscaras. Com argila eliminam-se os traços pessoais, para deixá-las o mais neutras possível. Segundo Lecoq, é o próprio ator quem deve fabricar sua máscara porque, assim, ao manuseá-la enquanto a confecciona, ele se familiarizará com ela. Constatamos isso em cada novo grupo de alunos-atores com quem trabalhamos.

\footnotetext{
2 No próprio ato de se modelar e observar um rosto, eleva-se o conhecimento da face humana como também o uso posterior da máscara para altos níveis. O processo material, o trabalho com a argila, a prática de modelagem, as investigações com o papel são os mais exaltantes e educativos entre os trabalhos manuais (tradução nossa).
} 
Chega o momento da papietagem, que é também um momento muito especial da confecção, pois todos trabalham com as mãos, colando pedaço por pedaço de papel, com a maior delicadeza e perfeição, para que a máscara tenha a leveza e a melhor modelagem possível. É importante ressaltar que, para que o aluno se sinta bem e a máscara alcance o objetivo técnico proposto, ela deve ter um bom acabamento, não ser pesada e, principalmente, se encaixar confortavelmente no rosto. Para que tudo funcione bem, tentamos proporcionar nesse momento da confecção muita tranquilidade em sala de aula. Os alunos podem puxar cantorias ou contar histórias regadas com muita emoção, principalmente no momento em que eles se vêm registrados naqueles pedaços de papel, feito por eles mesmos, pedaço por pedaço.

Em uma experiência distinta, no primeiro semestre de 2018, na UFSC, usamos máscaras confeccionadas por Blenda Trindade, uma artista plástica/diretora e ex-aluna do Curso de Artes Cênicas. Como são máscaras muito eficientes para o trabalho, organizamos então nossas aulas a partir delas. Deixamos de lado nesse semestre, portanto, a confecção da máscara no rosto de cada aluno, mas sentimos falta desse momento tão intenso e rico, acima descrito.

Para iniciarmos o uso das máscaras, temos como base o trabalho com os lenços, uma espécie de véu que cobre o rosto, para que os alunos comecem a se acostumar com a ausência de sua expressão facial. Esses exercícios nos dão base para passarmos para as máscaras. Na etapa seguinte, depois de termos já feito alguns exercícios, como o de caminhar com neutralidade, podemos fazer um ritual de uso da máscara. Isso consiste em cada aluno-ator pegar sua máscara e contemplá-la, manuseá-la, entrar em contato estreito com aquela que é passa a ser a imagem de seu rosto. Esse ritual é muito importante, tanto que os alunos de Jacques Copeau faziam isso durante oito dias antes de começar realmente a usar as máscaras. O grande ator Marcelo Moretti levava sempre no bolso sua máscara de Arlequino para poder olhá-la de vez em quando e acostumar-se com aquele pequeno artefato, que viria a ser seu mais valioso objeto de trabalho. 
Assim, podemos constatar que o ritual de reconhecimento e o contato com a máscara, mesmo em menor intensidade, como é o caso com nossos alunos, com os quais trabalhamos por somente um semestre, têm seus valores.

No dia em que os alunos colocam a máscara pela primeira vez podemos perceber o mesmo que Lecoq (1988, p. 46) descreve: "os movimentos dos olhos, que vão da direita para esquerda, dando a impressão de bichinhos enjaulados, com o corpo rijo e cabeça reta sem mexer, andando como robôs, e dando a impressão que não respiram, tamanha a ansiedade”.

É no momento do trabalho com a máscara neutra que a ação e a movimentação do aluno-ator ficam mais evidentes, pois não há mais a palavra, nem as expressões faciais. O corpo terá de ser capaz de transmitir tudo o que antes era falado ou mostrado no rosto. Tudo isso foi minuciosamente observado nos exercícios com os alunos. Eles se esbarravam, seus olhos iam de um lado para outro, notava-se no primeiro dia um nervosismo constante, os andares eram como o de robôs. Depois do ritual e após algumas caminhadas, costumamos nos sentar com os alunos e perguntar como se passou esse primeiro momento de uso da máscara. Seguem alguns comentários.

“Mesmo depois de contemplar a máscara e passar por este ritual, chegou o momento de colocar a máscara, senti uma grande falta de ar ao colocá-la, respirei fundo várias vezes, me concentrei e continuei a fazer os exercícios."

"Fiquei muito emocionado, mas consegui me concentrar, respirar fundo, e correu tudo super bem."

"Me senti asfixiada, mas depois de um tempinho para a adaptação os exercícios decorreram com facilidade.”

"Quase desisti, mas lembrei que eu mesma construí esta máscara, fiz um grande esforço e continuei. Agora ninguém mais me segura.”

Um dos alunos, por ser muito sensível, tremeu e chorou ao colocar a máscara pela primeira vez. Mas ele jamais deixou de fazer os exercícios por 
isso; pelo contrário, ele adorava e estava sempre disponível para participar. Sobre o andar dos alunos, cito Odette Aslan:

Perdemos o senso do espaço, e passamos trabalho para conservar o equilíbrio. Por isso inventamos a caminhada do Nô: não levantamos o pé, mas o arrastamos [...] Quando dirigimos nossa energia para um ponto exterior temos a impressão de caminharmos em grandes distâncias. (ASLAN, 1979, p. 187).

$\mathrm{O}$ andar, essa caminhada, característico no teatro Nô, adaptado por Aslan, muitas vezes recomendamos aos alunos, mas para eles era muito difícil conservar esse tipo de caminhar por muito tempo. É preciso estar sempre atento e concentrado ao usar a máscara, manter o olhar amplo, o andar Nô e a respiração.

Durante os exercícios, podemos perceber que, mesmo propondo um só gesto a todos, para que tudo fique muito parecido, e com todos usando suas máscaras neutras, ainda assim identificamos os detalhes e os gestos de cada um individualmente. Essa constatação nos remete às palavras de Jacques Lecoq:

A máscara neutra se aproxima de um denominador comum onde todo mundo pode se reconhecer. Eu trabalho cada ano com estudantes de 28 países, sob a máscara neutra. Não se sabe mais quem é quem. Mas é igualmente através dela que percebo as diferenças de cada um. Muito mais do que quando eles buscam seu próprio “Eu”, ou seu próprio personagem. (LECOQ, 1987, p. 19).

O que Lecoq nos relata observamos nas aulas práticas com os alunos da graduação. Nos exercícios com as máscaras, quando os atores deveriam mostrar o máximo de neutralidade, por mais que eles se esforçassem, deixavam sempre passar o seu "eu" corporal.

Peter Brook (1988) comenta esses mesmos fatores no uso da máscara ao afirmar que podemos colocar uma máscara em atores de diferentes países e com as mesmas habilidades técnicas e sensibilidade que obteremos resultados de igual qualidade, mas de formas totalmente diferentes, pois a junção de uma máscara e um ator produzirá resultados diferentes.

Ao exercício seguinte chamamos de "fazer a máscara respirar". O aluno deve se deitar e movimentar a cabeça no ritmo da respiração para dar a impressão de que a máscara respira. Muitos parecem estar mortos, mas basta um sutil movimento na cabeça e já se pode demonstrar ao público que 
a máscara está viva. Nesse exercício o que se busca é a relação perfeita entre a movimentação e a respiração.

A etapa seguinte é o exercício da triangulação. Consiste em cada aluno carregar um objeto de determinado ponto para outro, tentando triangular sempre que possível com o público. Nesse tipo de exercício podemos notar quem é exagerado nos movimentos e quem é contido demais. Existem aqueles que contam para o público duas ou três vezes o que vão fazer, e com isso sujam a imagem. Fica excessivo e causa riso. É interessante notar que a máscara pede certa quantidade de movimentos, nem exagerada e nem contida demais.

E o tempo também passa a ser outro. A máscara nos ajuda exatamente neste sentido: selecionar gestos mínimos para a realização de cada ação. O que é importante para um bom resultado é a repetição das ações, repetir e limpar cada gesto, para se chegar a um bom resultado. A máscara neutra nos ajuda no sentido de fazer nosso corpo falar. Diremos com nossos gestos e ações o que normalmente dizemos apenas com palavras. Segundo Lecoq,

Usar uma máscara neutra, não quer dizer não participar de situações nas quais a gente se encontra, mas apresentar-se nelas em estado de calma, sem conflitos prévios, nem ideias a priori, estar disponível aos acontecimentos, um pouco espantada, olhar de uma maneira ingênua, prestes a descobrir. (LECOQ, 1986, p. 2).

Lecoq nos leva para uma neutralidade além do corpo, aponta para um estado mental neutro, que seria a "limpeza de pensamentos", pois tudo aquilo que passa pelo mundo das ideias irá refletir em nossos corpos/ações. Esse tipo de máscara atua em dois campos inseparáveis: a mente e o corpo.

No decorrer das aulas os exercícios foram dando aos alunos-atores mais base e apoio no uso da máscara. E mesmo com algumas dificuldades pudemos notar a diferença no uso da máscara em grande parte da turma, comparando os exercícios realizados nos primeiros e nos últimos dias.

Nos últimos dias tudo fluía mais naturalmente. As improvisações com as máscaras aconteciam com mais naturalidade e segurança. Uma das alunas nos relatou: "É uma pena que as aulas tenham que acabar logo, porque só agora consigo fazer os exercícios tranquilamente. No começo me 
sentia asfixiada, tinha até ódio da minha máscara, tinha vontade de jogá-la longe, agora eu adoro minha máscara". Esse depoimento comprova a observação de Lecoq: "Por vezes há recusa, a máscara é tirada e jogada por terra pelo portador, sufocado, embora tenha bastante buracos, para que a respiração se faça normalmente" (LECOQ, 1988, p. 45).

Notamos que as reações foram as mais diversas possíveis: houve, em um extremo, aqueles que imediatamente tomaram consciência do corpo e se liberaram, e, no outro, aqueles que se fecharam, sem conseguir inicialmente bons resultados. Por outro lado, é importante ressaltar que todos, sem exceção, tiveram um notável crescimento com o decorrer das aulas, mesmo aqueles que tinham muita dificuldade na respiração, no caminhar, na concentração.

Ao usar a máscara neutra, a falta do olhar não era um problema. Afinal, a neutra é uma máscara mais egoísta, pois trata do trabalho do ator sobre si mesmo. Outros fatores importantíssimos estão presentes nesse processo. São os aspectos técnicos, como a triangulação, que consiste em pactuar com o público, indicando a presença de cada objeto ou ator/máscara.

Essa técnica consiste em dialogar com o público através do olhar. O importante é não deixar que efeitos contrários possam acontecer, como, por exemplo, triangular repetidamente numa sequência para o mesmo objeto, o que pode provocar o riso. A triangulação tem um efeito muito especial para o jogo da máscara, decididamente trazendo o público para o foco da cena.

\section{Máscaras larvárias}

Poderíamos continuar ainda por muito tempo no trabalho da máscara neutra, mas temos de dar um passo à frente e então apresentamos aos alunos as máscaras larvárias.

Estas são máscaras descobertas por Jacques Lecoq. Ele as viu em um carnaval na Suíça e, utilizando-as diferentemente, trouxe-as como objeto de estudo corporal para seu curso, um trabalho a partir da neutra. Tendo o aluno se identificado com a neutra, trabalhado o deslocamento, as 
percepções e as sensações, a máscara larvária entra como mais um caminho a trilhar, buscar, pesquisar.

As máscaras larvárias são grandes máscaras simples que não chegaram a definir-se num verdadeiro rosto humano. Nas palavras de Lecoq (2010, p. 96), "Elas têm, apenas, ou um nariz grande, ou uma forma de bola, ou parecem uma ferramenta de impacto ou de corte".

A construção dessa máscara deve levar em conta o fato de ser maior que uma máscara normal. As formas devem ser simples, mas conter aspectos sociais reconhecíveis e características culturais bem definidas para ajudar na construção de imagens para os jogos de cena.

A primeira e mais importante constatação na percepção dos alunosatores foi sobre o olhar, pois, sem perceber o outro, não há jogo. Seria preciso sair do universo da máscara neutra e enfrentar o que estava para além, mas sem se esquecer de si mesmo, de seu corpo, que irá compor a máscara larvária. Para tanto, trabalhamos com alguns jogos de olhares. O ouvir também é uma das regras para que o jogo aconteça. Essas pequenas orientações ajudam na composição dos corpos a partir de cada máscara, trabalhando, assim, a máscara e a contramáscara, fazendo com que a larvária exista verdadeiramente na cena.

Construímos algumas máscaras larvárias em 2003, mas poucas vezes as usamos em sala de aula. Foi a partir dessas máscaras que uma aluna, Daniela Viola, ao se apaixonar por elas, montou uma pequena equipe e nos chamou para trabalhar com eles. Aceitamos o convite, e de vez em quando lhes propúnhamos alguns exercícios. Eles trabalhavam bastante e nos chamavam para lhes dar novos exercícios. Desse modo, passamos a dar uma espécie de orientação ao grupo.

As máscaras larvárias fizeram tanto sucesso entre esses alunos, assim como as neutras, que orientamos duas pesquisas de trabalho de 
conclusão de curso (TCC) ${ }^{3}$ e um projeto PIBIC. Deste surgiu um espetáculo que tem como base as larvárias. ${ }^{4}$

O espetáculo circula ainda hoje no Estado de Santa Catarina e também já foi apresentado na cidade de Natal, RN. Com direção de Blenda Trindade, o espetáculo utiliza máscaras construídas pela própria diretora e faz um jogo com as máscaras larvárias e com "personagens" que se estruturaram a partir das larvárias. ${ }^{5}$ Jacques Lecoq, que foi quem nos apresentou as máscaras larvárias, jamais as utilizou como personagens, mas esse grupo o faz, e percebemos que elas funcionam muito bem. Inclusive, as larvárias utilizadas como personagens nos trazem um ar todo clownesco nesse espetáculo.

Mesmo existindo há tanto tempo, as máscaras ainda são motivo de estudos e de pesquisas na contemporaneidade. Descobrimos no dia a dia dentro da sala de aula o quanto elas ajudam no trabalho do aluno-ator. Podemos ver a dimensão do trabalho das máscaras partindo das neutras, passando pelas larvárias e chegando aos personagens sejam eles quais forem.

\section{Reflexões finais}

Durante as aulas fica patente a eficácia das improvisações e do uso da máscara neutra para a concentração e o conhecimento do próprio corpo dos alunos-atores. Pudemos perceber esse ganho durante nossas aulas trabalhando com as máscaras neutras, substituindo a palavra excessiva por gestos e ações. Com isso tentamos negar a interpretação naturalista que está tão enraizada na maioria de nossos alunos-atores, fazendo, assim, o que

\footnotetext{
3 TCC defendido na Universidade Federal de Santa Catarina (UFSC) em 2018 por Blenda Emanuelle da Trindade. A Linguagem Larvárica: caderno de direção da montagem de Pegando do Resto. Orientação: Maria de Fatima de Souza Moretti (Sassá Moretti).

${ }_{4}^{4}$ Projeto de Pesquisa PIBIC realizado de $1^{\circ}$ de agosto de 2017 a 31 de julho de 2018, "O texto em cena - transformando palavras em imagens". Bolsista PIBIC: Blenda Emanuelle da Trindade. Coordenação: Maria de Fátima de Souza Moretti.

5 Pegando do Resto, espetáculo que tem como base dramatúrgica o texto Esperando Godot, de Samuel Beckett, com duração de $55 \mathrm{~min}$, tem a direção de Blenda Trindade e a participação dos alunos-atores PititaBlasius, Igor Gomes, Maykon José, João Quinalha e Laura W. Gedoz. Foram 12 apresentações até o momento, no Cena Emergente - Sesc Prainha, $1^{\circ}$ EBA - Udesc, Experimenta UFSC, V Cena Emergente do Sesc, $70^{a}$ Reunião Anual do SBPC, $23^{\circ}$ Festival Isnard de Azevedo e III SBDR - UFSC.
} 
muitos diretores e encenadores do princípio do século já almejavam: acabar com as interpretações psicológicas, os clichês e as afetações.

Partimos da neutra para chegarmos às outras máscaras, como as larvárias e também as de personagens. Com essa experiência, confirmamos a eficácia dessa mistura: a neutra ajuda a chegar a alguns objetivos do ator ideal; a larvária ajuda no jogo corporal. $\mathrm{O}$ andar deve ser o mais neutro possível, os exercícios de caminhar como no teatro Nô ajudam nesse sentido de neutralidade. Já o sentido de frontalidade da máscara é muito importante, pois, se perdemos o olhar da máscara, ela passa a inexistir.

A triangulação, um dos princípios da máscara que herdamos da Commedia del l'Arte para esse exercício, pede que a máscara tenha sempre com o público uma relação frontal. O olhar deve conduzir a ação, pois, se isso não acontecer, o gesto perderá o sentido. E se a ação for feita sem a triangulação, o público se confundirá. O interessante é que qualquer passo em falso é dilatado, mostrando claramente as indecisões da ação. Portanto, é preciso firmeza e determinação ao se trabalhar na cena, e a máscara neutra ajuda nessa busca.

A máscara larvária é ainda embrionária, podemos percebê-la como ingênua, clownesca, doce e tantas outras denominações. Ela está sempre em estado de busca e descobertas.

Partindo desta reflexão, concluímos que o trabalho de uso das máscaras em sala de aula contribui em muito no percurso de formação e aprimoramento do trabalho do aluno-ator contemporâneo. 


\section{REFERÊNCIAS}

AMARAL, Ana Maria. Teatro de formas animadas. São Paulo: Edusp,1991.

AMARAL, Ana Maria. O ator e seus duplos. São Paulo: Senac, 2002.

ASLAN, Odette. El actor em el siglo XX. Barcelona: Gustavo Gill, 1979.

BING, Suzanne. Le [mardi] 22 juin [1920 Registres VI. L'Ecole du Vieux-

Colombier ]. In: COPEAU, Jacques. Registres VI. L'Ecole du VieuxColombier. Textesétablis, présentes et annotés par Claude Sicard. Paris: Gallimard, 2000.

BROOK, Peter.Mensonge et adjectifsuperbe. In:ASLAN, Odette; BABLET, Denis. Le masque : du rite au theatre. Paris: CNRS, 1985. p. 193-207.

CRAIG, Edward Gordon. Da arte do teatro. Lisboa: Arcádia, 1963.

DANI, Sandra. A máscara, seu sentido e seu uso no treinamento do ator. Porto Arte - Revista do Instituto de Artes da UFRGS, v. 1, n. 1, p. 83-90, 1990.

FREIXE, Guy. A máscara «nobre» na Escola do Vieux-Colombier (19211924). In: FREIXE, Guy; DUSIGNE, Jean-François. As utopias da máscara nas cenas europeias do século XX. Tradução inédita de José Ronaldo Faleiro. Montpellier: l'Entretemps, 2010. p. 119-134. (Coleção LesVoies de L'Acteur).

FO, Dario. Tire as mãos da máscara. Cadernos de Teatro, Rio de Janeiro, n. 125 , p. 6-8, 1991.

FO, Dario. Manual mínimo do ator. São Paulo: Senac, 1998.

LECOQ, Jacques. Rôle du masque dans la formation de l'acteur. In: ASLAN, Odette; BABLET, Denis (Ed.). Le masque : du riteauthéâtre. Paris: CNRS, 1985. p. 265-269.

LECOQ, Jacques. Le jeu masque. In: LECOQ, Jacques (Org.). Le théâtredugeste : mimes et acteurs. Paris: Bordas, 1987.

LECOQ, Jacques. O corpo poético: uma pedagogia da criação teatral.São Paulo: Senac; Sesc/SP, 2010.

LOPES, Elizabeth Pereira.Copeau e a máscara.In: COSTA, Felisberto Sabino (Org.). A máscara e a formação do ator. São Paulo: Edusp, 1991. 
PAVIA, Marguerita. Mascaras teatrales. México: Gaceta, 1994.

RUDLIN, Jonh. Jacques Copeau: the request for sincerity. In: HODGE, Alison (Ed.). Actor traning. 2. ed. New York: Routledge. 2010. p. 43-62.

SPOLIN, Viola. Improvisação para o teatro. São Paulo: Perspectiva, 2010.

Recebido em março de 2019.

Aprovado em abril de 2019.

Publicado em junho de 2019. 